\title{
Transport mode choice and body mass index: Cross-sectional and longitudinal evidence from a European-wide study
}

Dons, Evi ; Rojas-Rueda, David ; Anaya-Boig, Esther ; Avila-Palencia, Ione ; Brand, Christian ; Cole-Hunter, Tom ; de Nazelle, Audrey ; Eriksson, Ulf ; Gaupp-Berghausen, Mailin ; Gerike, Regine ; Kahlmeier, Sonja ; Laeremans, Michelle ; Mueller, Natalie ; Nawrot, Tim ; Nieuwenhuijsen, Mark J ; Orjuela, Juan Pablo ; Racioppi, Francesca ; Raser, Elisabeth ; Standaert, Arnout ; Int Panis, Luc ; Götschi, Thomas

\begin{abstract}
BACKGROUND In the fight against rising overweight and obesity levels, and unhealthy urban environments, the renaissance of active mobility (cycling and walking as a transport mode) is encouraging. Transport mode has been shown to be associated to body mass index (BMI), yet there is limited longitudinal evidence demonstrating causality. We aimed to associate transport mode and BMI cross-sectionally, but also prospectively in the first ever European-wide longitudinal study on transport and health. METHODS Data were from the PASTA project that recruited adults in seven European cities (Antwerp, Barcelona, London, Oerebro, Rome, Vienna, Zurich) to complete a series of questionnaires on travel behavior, physical activity levels, and BMI. To assess the association between transport mode and BMI as well as change in BMI we performed crude and adjusted linear mixed-effects modeling for cross-sectional $(\mathrm{n}=7380)$ and longitudinal $(\mathrm{n}=2316)$ data, respectively. RESULTS Cross-sectionally, BMI was $0.027 \mathrm{~kg} / \mathrm{m}(95 \%$ CI 0.015 to 0.040$)$ higher per additional day of car use per month. Inversely, BMI was $-0.010 \mathrm{~kg} / \mathrm{m}$ (95\% CI -0.020 to -0.0002) lower per additional day of cycling per month. Changes in BMI were smaller in the longitudinal within-person assessment, however still statistically significant. BMI decreased in occasional (less than once per week) and non-cyclists who increased cycling $(-0.303$ $\mathrm{kg} / \mathrm{m}, 95 \%$ CI -0.530 to -0.077 ), while frequent (at least once per week) cyclists who stopped cycling increased their BMI $(0.417 \mathrm{~kg} / \mathrm{m}, 95 \%$ CI 0.033 to 0.802). CONCLUSIONS Our analyses showed that people lower their BMI when starting or increasing cycling, demonstrating the health benefits of active mobility.
\end{abstract}

DOI: https://doi.org/10.1016/j.envint.2018.06.023

Posted at the Zurich Open Repository and Archive, University of Zurich

ZORA URL: https://doi.org/10.5167/uzh-152336

Journal Article

Accepted Version

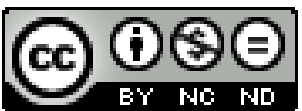

The following work is licensed under a Creative Commons: Attribution-NonCommercial-NoDerivatives 4.0 International (CC BY-NC-ND 4.0) License.

Originally published at: 
Dons, Evi; Rojas-Rueda, David; Anaya-Boig, Esther; Avila-Palencia, Ione; Brand, Christian; ColeHunter, Tom; de Nazelle, Audrey; Eriksson, Ulf; Gaupp-Berghausen, Mailin; Gerike, Regine; Kahlmeier, Sonja; Laeremans, Michelle; Mueller, Natalie; Nawrot, Tim; Nieuwenhuijsen, Mark J; Orjuela, Juan Pablo; Racioppi, Francesca; Raser, Elisabeth; Standaert, Arnout; Int Panis, Luc; Götschi, Thomas (2018). Transport mode choice and body mass index: Cross-sectional and longitudinal evidence from a European-wide study. Environment international, 119:109-116.

DOI: https://doi.org/10.1016/j.envint.2018.06.023 


\section{Transport Mode Choice and Body Mass Index: Cross-Sectional and Longitudinal Evidence from a European-Wide Study}

Dons, Evi ${ }^{1,2, *}$; Rojas-Rueda, David ${ }^{3,4,5}$; Anaya-Boig, Esther ${ }^{6}$; Avila-Palencia, lone ${ }^{3,4,5}$; Brand, Christian ${ }^{7}$; Cole-Hunter, Tom ${ }^{3,4,5,8}$; de Nazelle, Audrey ${ }^{6}$; Eriksson, Ulf ${ }^{9}$; Gaupp-Berghausen, Mailin ${ }^{10}$; Gerike, Regine ${ }^{11}$; Kahlmeier, Sonja ${ }^{12}$; Laeremans, Michelle ${ }^{2,13}$; Mueller, Natalie ${ }^{3,4,5}$; Nawrot, Tim ${ }^{1,14}$; Nieuwenhuijsen, Mark J ${ }^{3,4,5}$; Orjuela, Juan Pablo ${ }^{6}$; Racioppi, Francesca ${ }^{15}$; Raser, Elisabeth ${ }^{10}$; Standaert, Arnout ${ }^{2}$; Int Panis, Luc ${ }^{2,13}$; Götschi, Thomas ${ }^{12}$

\footnotetext{
${ }^{1}$ Centre for Environmental Sciences, Hasselt University, Martelarenlaan 42, 3500 Hasselt, Belgium

${ }^{2}$ Flemish Institute for Technological Research (VITO), Boeretang 200, 2400 Mol, Belgium

${ }^{3}$ ISGlobal, C/Dr. Aiguader 88, 08003 Barcelona, Spain

${ }^{4}$ Universitat Pompeu Fabra (UPF), C/Dr. Aiguader 88, 08003 Barcelona, Spain

${ }^{5}$ CIBER Epidemiología y Salud Pública (CIBERESP), C/Monforte de Lemos 3-5, 28029 Madrid, Spain

${ }^{6}$ Centre for Environmental Policy, Imperial College London, Exhibition Road, South Kensington Campus, SW7 2AZ London, UK

${ }^{7}$ Transport Studies Unit, University of Oxford, South Parks Road, Oxford, OX1 3QY, UK

8 Department of Environmental and Radiological Health Sciences, Colorado State University, Fort Collins, Colorado, USA

${ }^{9}$ Trivector Traffic, Barnhusgatan 16, Stockholm, Sweden

${ }^{10}$ University of Natural Resources and Life Sciences Vienna, Institute for Transport Studies, Peter-Jordan-Straße 82, 1190 Vienna, Austria

${ }^{11}$ Dresden University of Technology, Chair of Integrated Transport Planning and Traffic Engineering, 01062 Dresden, Germany

12 Physical Activity and Health Unit, Epidemiology, Biostatistics and Prevention Institute, University of Zurich, Seilergraben 49,8001 Zurich, Switzerland

${ }^{13}$ Transportation Research Institute (IMOB), Hasselt University, Wetenschapspark 5/6, 3590 Diepenbeek, Belgium

${ }^{14}$ Environment \& Health Unit, University of Leuven, Herestraat 49, box 706, 3000 Leuven, Belgium

${ }^{15}$ World Health Organization Regional Office for Europe, Denmark
}

* Correspondence to: dr Evi Dons, Centre for Environmental Sciences, Hasselt University, Martelarenlaan 42, 3500 Hasselt, Belgium

Phone: +32 143351 90, e-mail: evi.dons@uhasselt.be 
This is a post-peer-review, pre-copyedit version of an article published in Environment International. The final authenticated version is available online at: https://doi.org/10.1016/i.envint.2018.06.023

\section{Abstract}

\section{Background}

In the fight against rising overweight and obesity levels, and unhealthy urban environments, the renaissance of active mobility (cycling and walking as a transport mode) is encouraging. Transport mode has been shown to be associated to body mass index (BMI), yet there is limited longitudinal evidence demonstrating causality. We aimed to associate transport mode and BMI cross-sectionally, but also prospectively in the first ever European-wide longitudinal study on transport and health.

\section{Methods}

Data were from the PASTA project that recruited adults in seven European cities (Antwerp, Barcelona, London, Oerebro, Rome, Vienna, Zurich) to complete a series of questionnaires on travel behavior, physical activity levels, and BMI. To assess the association between transport mode and BMI as well as change in BMI we performed crude and adjusted linear mixed-effects modeling for cross-sectional $(n=7380)$ and longitudinal $(n=2316)$ data, respectively.

\section{Results}

Cross-sectionally, BMI was $0.027 \mathrm{~kg} / \mathrm{m}^{2}$ (95\% $\mathrm{Cl} 0.015$ to 0.040 ) higher per additional day of car use per month. Inversely, BMI was $-0.010 \mathrm{~kg} / \mathrm{m}^{2}(95 \% \mathrm{Cl}-0.020$ to -0.0002$)$ lower per additional day of cycling per month. Changes in BMI were smaller in the longitudinal within-person assessment, however still statistically significant. BMI decreased in occasional (less than once per week) and non-cyclists who increased cycling $\left(-0.303 \mathrm{~kg} / \mathrm{m}^{2}, 95 \% \mathrm{Cl}-0.530\right.$ to -0.077$)$, while frequent (at least once per week) cyclists who stopped cycling increased their BMI (0.417 $\mathrm{kg} / \mathrm{m}^{2}, 95 \% \mathrm{Cl} 0.033$ to 0.802 ).

\section{Conclusions}

Our analyses showed that people lower their BMI when starting or increasing cycling, demonstrating the health benefits of active mobility.

Keywords: body mass index, BMI, physical activity, active mobility, walking, cycling 
This is a post-peer-review, pre-copyedit version of an article published in Environment International. The final authenticated version is available online at: https://doi.org/10.1016/j.envint.2018.06.023

\section{Introduction}

Europe is facing an overweight and obesity epidemic (Berghöfer and others 2008). A relatively new approach to tackle this problem is through increasing physical activity levels as part of daily routines, which includes commuting to work or education, notably through walking or cycling (referred to as active mobility). While a rise in population obesity coincides with a decrease in physical activity, countries where active mobility is most common also happen to have the lowest obesity rates (Bassett and others 2008; Prentice and Jebb 1995; Pucher and others 2010). Although this association does not prove causality, it warrants further investigation.

The use of different transport modes, e.g. car driving, walking and cycling, requires different energy expenditure and this may be related to body weight and body mass index (BMI). Wanner and colleagues reviewed 30 studies (mainly cross-sectional studies, with only one longitudinal study in middle-aged men) evaluating associations between the use of active mobility and body weight: in 25 of these studies an association was found (Wanner and others 2012). There is also evidence that active mobility adds to total physical activity, and that physical activity reduces body weight (Celis-Morales and others 2017a; Physical Activity Guidelines Advisory Committee 2008; Wanner and others 2012). These associations suggest that physical activity may act as a mediator in the relationship between active mobility and body weight. Similarly, within transport modes there may be differences in body weight and BMI that could be explained by a different use. Martin and colleagues found a larger reduction in BMI among those switching to active mobility with journey times over 30 minutes compared to those traveling for less than 10 minutes (Martin and others 2015). Celis-Morales and colleagues found that cycling longer distances was more strongly associated with health outcomes (incident cardiovascular disease, cancer, and mortality) than cycling shorter distances; and cycling shorter distances was better than no cycling (Celis-Morales and others 2017b). Considering all of this, it seems plausible that active mobility acts as a key factor in body weight management through transport-related physical activity. However, this association may also be driven by reverse causality: lean individuals might be more likely to walk or cycle (further) than overweight individuals (Ekelund and others 2008; Ekelund and others 2017; Wanner and others 2012).

This study aimed to address several gaps in the existing literature. Foremost, we included a longitudinal assessment to investigate the association between active mobility and $\mathrm{BMI}-$ longitudinal or intervention studies are essential to study the direction and size of the effect 
and changes over time, and estimate the importance of self-selection or other confounding variables (Faulkner and others 2009; Xu and others 2013). The few longitudinal studies that are available are national studies, mainly in the UK and US; to the best of our knowledge, no international multicenter studies have been reported (Bell and others 2002; Braun and others 2016; Flint and others 2016; Martin and others 2015; Mytton and others 2016). We included seven European cities in our study, with different baseline levels of BMI and physical activity levels, different climates, different built environment and transport infrastructure, and a varying share of transport modes to increase generalizability and representativeness (Table S1).

There is a lack of standardized definitions and measurements (self-reported or measured) to identify a dominant transport mode or to quantify the amount of active mobility leading to imprecise exposure assessment and bias in the results (Wanner and others 2012; Xu and others 2013). The heterogeneity of studies makes it nearly impossible to perform a metaanalysis or to compare effect sizes found in different studies. Moreover, a number of other factors, like occupational or leisure-time physical activity or diet, could alter the association between transport mode and BMI (Aadahl and others 2007; Aires and others 2003; CelisMorales and others 2017a; Flint and Cummins 2016; Kim and others 2017).

The overall aim of this study is therefore to evaluate the association between transport mode choice and $\mathrm{BMI}$ in an international multicenter longitudinal study, while accounting for a number of known influencers. Additionally, we wanted to compare the cross-sectional and the longitudinal approach. 
This is a post-peer-review, pre-copyedit version of an article published in Environment International. The final authenticated version is available online at: https://doi.org/10.1016/j.envint.2018.06.023

\section{Materials \& methods}

Study design

An online questionnaire on physical activity, travel behavior and health was developed as part of the pan-European PASTA project (Physical Activity through Sustainable Transport Approaches) (Dons and others 2015). Participants were opportunistically recruited in seven cities (Antwerp, Barcelona, London, Oerebro, Rome, Vienna, Zurich). Several recruitment methods were applied simultaneously with the most successful being direct targeting of local stakeholders, community groups, and workplaces, and the use of social media. In order to have sufficiently large sample sizes for different transport modes, users of rare transport modes were oversampled with targeted actions. A sample size of 2000 registrations per city was aimed for, taking into consideration attrition during follow-up. Finally, 10,722 participants entered the study on a rolling basis between November 2014 and November 2016 by filling out a baseline questionnaire ( $\left.t_{0}\right)$. In November 2016 all participants who finished the baseline questionnaire were invited to complete a final questionnaire $\left(t_{1}\right)$. Short follow-up questionnaires were sent every two weeks between $t_{0}$ and $t_{1}$ (Dons and others 2015). To increase response rates and ensure understanding of the questions, all questionnaires could be completed in the local language. Data quality and completeness was guaranteed by including a number of programming rules and constraints in the questionnaires. Participants had to be 18 years of age (16 years in Zurich) or older, and had to give informed consent at registration. Data handling and ethical considerations regarding confidentiality and privacy of the information collected, are reported in the study protocol (Dons and others 2015).

\section{Outcome variables}

Body mass index (BMI; weight $(\mathrm{kg}) /$ height $\left(\mathrm{m}^{2}\right)$ ), as a direct risk indicator of disease, was the outcome of interest. 8789 participants provided at least a valid height and weight $\left(14 \mathrm{~kg} / \mathrm{cm}^{2}<\right.$ $\mathrm{BMI}<45 \mathrm{~kg} / \mathrm{cm}^{2}$ ) in the baseline questionnaire; 3292 of them additionally provided a valid height and weight in the final questionnaire. Height and weight were self-reported, but weights were well correlated in a validation subsample of 119 participants using direct measurements ( $r=0.95$; underreported by $2.4 \mathrm{~kg}$ on average; supplemental material). Differences between self-reported and measured weight were non-differential between the different transport modes. Absolute change in BMI over the follow-up period was calculated by subtracting $t_{0}$ data from $t_{1}$ data (for the longitudinal analysis).

\section{Exposure variables}


This is a post-peer-review, pre-copyedit version of an article published in Environment International. The final authenticated version is available online at: https://doi.org/10.1016/j.envint.2018.06.023

Non-recreational transport mode usage was quantified using the question "How often do you currently use each of the following methods of travel to get to and from places?", rated on a five-point scale ranging from "Daily or almost daily" to "Never" (Table S2). Modes considered were walking, cycling, e-biking (electrically assisted cycling), motorcycle or moped, public transport, and car or van. Subsequently, frequencies were assigned to each of the categories, transforming this into a days-per-month variable ("Daily or almost daily" = 24 days per month; "on 1-3 days per week" = 8 days per month; "on 1-3 days per month" = 2 days per month; "Less than once per month" = 1 day per month; "Never" = 0 days per month). For the longitudinal assessment, absolute changes in frequency between $t_{0}$ and $t_{1}$ were calculated. Secondly, a categorical variable looking at cycling frequency was considered: participants were categorized as frequent cyclist (at least once per week), occasional cyclist (less than once per week), or non-cyclist. Changes between groups were considered in the longitudinal study.

\section{Covariates}

Several covariates were hypothesized to possibly confound the association between BMI and transport mode (Flint and Cummins 2016; Mytton and others 2016). Socio-demographic covariates considered in the analyses were age, sex, and education level. Occupational physical activity and leisure-time physical activity were included to adjust for other physical activity; both were estimated using the Global Physical Activity Questionnaire, which was included in the PASTA questionnaires (Bull and others 2009). Lifestyle/disease proxies (self-rated health; sedentary time) were included as health covariates. All of the covariates were self-reported. Most of the covariates were reported at both $t_{0}$ and $t_{1}$, except for the covariates that were considered time-invariant (sex, education level). Physical activity was reported at $t_{0}$, and multiple times between $t_{0}$ and $t_{1}$, but not at $t_{1}$; therefore, the average physical activity between $t_{0}$ and $t_{1}$ was used as proxy for physical activity at $t_{1}$. In the longitudinal analysis, the number of days between $t_{0}$ and $t_{1}$ was included as a covariate (Braun and others 2016).

\section{Statistical analysis}

Bivariate analyses were performed to assess the association between $\mathrm{BMI}$, the exposure variables, and the potential covariates. Only covariates with $p$-value $<0.1$ (in either the crosssectional or the longitudinal models, or in both) were included in the linear mixed-effects models. Two different approaches were followed. First, a cross-sectional analysis was performed to identify differences in BMI between the different transport mode users at $t_{0}$. Second, a longitudinal analysis was performed to assess the change in BMI that results from a change in travel behavior between $t_{0}$ and $t_{1}$. For both approaches, the cross-sectional and the 
longitudinal analysis, we used linear mixed-effects models with city as a random effect. Three regression models were fitted: (0) unadjusted; (1) adjusted for socio-demographic covariates: sex, age, education level; and (2) adjusted for all covariates from model 1 and additionally other covariates of interest (as identified by the literature): self-rated health, occupational physical activity, leisure-time physical activity, and sedentary time. In the longitudinal models, sex, age at baseline, baseline education level, baseline BMI, and city were hypothesized timeinvariant covariates; and change in self-rated health, change in lifestyle, change in occupational and leisure-time physical activity, change in sedentary time, and time between $t_{0}$ and $t_{1}$ were hypothesized time-varying covariates between baseline and follow up.

Interaction by sex was investigated with Wald tests. There was no statistically significant interaction of sex in the fully-adjusted models, but for some modes near-significant interactions were observed, so we decided to test all models' sensitivity to different sexes. We also tested the models' sensitivity to a number of other factors: age, being overweight, participants that moved houses during follow-up (Braun and others 2016; Mytton and others 2016), participants with a life changing event (moved house, new job or new job location, birth or adoption of a child in the household, stopped working, married, child / someone has left the household) (Allender and others 2008), time between $t_{0}$ and $t_{1}$, and city (Table S3). Potential mediation by transport-related physical activity between transport mode and BMI was also assessed (VanderWeele 2016). Only observations without missing data were included. R statistical software v3.3.2 was used for all analyses. A directed acyclic graph presenting the hypothesized causal structure is included in the supplemental material (Figure S1). 
This is a post-peer-review, pre-copyedit version of an article published in Environment International. The final authenticated version is available online at: $\underline{\text { https://doi.org/10.1016/j.envint.2018.06.023 }}$

\section{Results}

The final sample was well balanced between male and female, and between the seven cities. Participants were generally reporting to be in good health, and aged between 16 and 91. Walking, public transport and bikes were the most frequent transport modes among our participants (Table 1). Transport mode usage was similar between sexes, with a slightly higher prevalence of male cyclists and female public transport users. Non-respondents to the final questionnaire (at $t_{1}$ ) were statistically different from the sample responding to both questionnaires; however, there was no difference in BMI, sex, transport-related and leisuretime physical activity level, and transport mode usage of e-bike, motorcycle, and walk. Both questionnaires $\left(t_{0}\right.$ and $t_{1}$ ) were completed $492 \pm 202$ days apart.

At $t_{1}$, participants reported less frequent use of the bike (-1.25 days/month) and of walking (1.70 days/month), and they increased car use (+0.62 days/month) compared to $t_{0}$. The prevalence of switching between cycling categories was 22\%: 369 participants reported less cycling and 152 reported more cycling, 1795 participants did not change their cycling behaviour (Table S4).

Table 1: Characteristics of outcome, exposure and other covariates

\begin{tabular}{|c|c|c|c|c|}
\hline & $\begin{array}{l}\text { Respondents for cross- } \\
\text { sectional analysis at to } \\
(n=7380)\end{array}$ & $\begin{array}{l}\text { Respondents for } \\
\text { longitudinal analysis at to } \\
\text { ( } n=2316)\end{array}$ & $\begin{array}{l}\text { Sign } \\
\text { different at } \\
t_{0} \text { ? }\end{array}$ & $\begin{array}{l}\text { Respondents for } \\
\text { longitudinal analysis at } t_{1} \\
(n=2316)\end{array}$ \\
\hline \multicolumn{5}{|c|}{ m } \\
\hline All & $23.87(3.92)$ & $23.87(3.85)$ & No & $23.90(3.82)$ \\
\hline Male & $24.62(3.61)$ & $24.55(3.53)$ & No & $24.54(3.54)$ \\
\hline Female & $23.19(4.06)$ & $23.22(4.02)$ & No & $23.30(3.97)$ \\
\hline \multicolumn{5}{|l|}{ Height [m] } \\
\hline All & $1.72(0.09)$ & $1.72(0.09)$ & No & $1.72(0.09)$ \\
\hline Male & $1.79(0.07)$ & $1.78(0.07)$ & No & $1.79(0.07)$ \\
\hline Female & $1.67(0.07)$ & $1.67(0.07)$ & No & $1.67(0.07)$ \\
\hline \multicolumn{5}{|l|}{ Weight $[\mathrm{kg}]$} \\
\hline All & $71.09(14.06)$ & $71.12(13.71)$ & No & $71.30(13.63)$ \\
\hline Male & $78.57(12.30)$ & $78.17(11.92)$ & No & $78.26(12.00)$ \\
\hline Female & $64.33(11.97)$ & $64.50(11.85)$ & No & $64.76(11.70)$ \\
\hline Age & $39.50(12.53)$ & $40.66(12.16)$ & $* * *$ & $42.00(12.15)$ \\
\hline Sex & & & No & \\
\hline Male & $3503(47 \%)$ & $1122(48 \%)$ & & NA \\
\hline Female & 3877 (53\%) & $1194(52 \%)$ & & NA \\
\hline \multicolumn{5}{|c|}{ Transport mode usage (days per month) } \\
\hline Car & $6.44(7.70)$ & $5.73(7.03)$ & $* * *$ & $6.35(7.23)$ \\
\hline Bike & $10.90(10.73)$ & $11.69(10.82)$ & $* *$ & $10.44(10.67)$ \\
\hline E-bike & $0.62(3.46)$ & $0.69(3.68)$ & No & $0.96(4.28)$ \\
\hline Motorcycle / moped & $1.28(4.85)$ & $1.12(4.53)$ & No & $1.12(4.48)$ \\
\hline Public transport & $11.94(10.20)$ & $12.39(10.17)$ & . & $11.73(9.92)$ \\
\hline Walk & $19.27(8.26)$ & $19.48(8.06)$ & No & $17.78(8.67)$ \\
\hline Cycling category & & & $*$ & \\
\hline Non-cyclist & $1663(23 \%)$ & $476(21 \%)$ & & $606(26 \%)$ \\
\hline Occasional cyclist & $1680(23 \%)$ & $500(22 \%)$ & & $478(21 \%)$ \\
\hline Frequent cyclist & 4037 (55\%) & $1340(58 \%)$ & & $1234(53 \%)$ \\
\hline City & & & $* * *$ & \\
\hline Antwerp & 1147 (16\%) & $389(17 \%)$ & & NA \\
\hline Barcelona & $1247(17 \%)$ & $430(19 \%)$ & & NA \\
\hline London & 865 (12\%) & $263(11 \%)$ & & NA \\
\hline Oerebro & 759 (10\%) & $143(6 \%)$ & & NA \\
\hline
\end{tabular}


This is a post-peer-review, pre-copyedit version of an article published in Environment International. The final authenticated version is available online at: https://doi.org/10.1016/i.envint.2018.06.023

\begin{tabular}{|c|c|c|c|c|}
\hline Rome & $1328(18 \%)$ & $305(13 \%)$ & & NA \\
\hline Vienna & $1023(14 \%)$ & $422(18 \%)$ & & NA \\
\hline Zurich & $1011(14 \%)$ & $364(16 \%)$ & & NA \\
\hline Self-rated health & & & $* * *$ & \\
\hline Excellent & $708(10 \%)$ & $249(11 \%)$ & & $254(11 \%)$ \\
\hline Very good & $2814(38 \%)$ & $950(41 \%)$ & & $1003(43 \%)$ \\
\hline Good & $2928(40 \%)$ & 895 (39\%) & & $843(36 \%)$ \\
\hline Fair & $826(11 \%)$ & $202(9 \%)$ & & $196(8 \%)$ \\
\hline Poor & $104(1 \%)$ & $20(1 \%)$ & & $20(1 \%)$ \\
\hline Education level & & & ** & \\
\hline No degree & $20(0 \%)$ & $3(0 \%)$ & & NA \\
\hline Primary education & $90(1 \%)$ & $22(1 \%)$ & & NA \\
\hline Secondary education / Further education & $1897(26 \%)$ & $527(23 \%)$ & & NA \\
\hline Higher education / University education & $5373(73 \%)$ & $1764(76 \%)$ & & NA \\
\hline GPAQ: occupational PA (metminutes) & $870.32(2529.19)$ & $776.13(2310.25)$ & . & $656.53(1624.47)^{\dagger}$ \\
\hline GPAQ: transport PA (metminutes) & $1568.51(1951.12)$ & $1524.73(1637.64)$ & No & $1485.51(1174.94)^{\dagger}$ \\
\hline GPAQ: leisure time PA (metminutes) & $1606.02(2303.97)$ & $1566.61(2126.75)$ & No & $1196.55(1228.64)^{\dagger}$ \\
\hline GPAQ: sedentary time (minutes) & $466.05(194.88)$ & $489.52(192.86)$ & $* * *$ & $480.38(209.02)^{\dagger}$ \\
\hline
\end{tabular}

Data are mean (SD) or $\mathrm{n}(\%)$. BMI: body mass index; GPAQ: global physical activity questionnaire; PA: physical activity.

Statistical significance: $0 * * * 0.001 * * 0.01 * 0.05 \cdot 0.1$

${ }^{+}$Average value from prospective analysis between $t_{0}$ and $t_{1}$.

\section{Cross-sectional analysis}

Across all models, statistically significant associations between BMI and transport mode usage were observed for several transport modes (Table 2). In the fully-adjusted model, BMI was $0.027 \mathrm{~kg} / \mathrm{m}^{2}(95 \% \mathrm{Cl} 0.015$ to 0.040$)$ higher per additional day of car use per month. For an average individual in the sample (height: $1.72 \mathrm{~m}$ ) an additional day of car driving per week translates into a weight difference of $0.32 \mathrm{~kg}$. Significant associations were found for car (increases $\mathrm{BMI}$ ), bike (decreases $\mathrm{BMI}$ ), and motorcycle (increases $\mathrm{BMI}$ ), and a near-significant association $(0.05<p<0.10$ ) was found for e-bike (increases BMI). No statistically significant associations were found for public transport use $(p=0.17)$ or walking $(p=0.46)$. Adjusting for age and sex changed the estimates in the partly and the fully adjusted models (model 1 and model 2) compared to the unadjusted model (model 0); the addition of self-rated health in the fully adjusted model (model 2) lowered the estimate for bike compared to the partly adjusted model (model 1). The results suggest a graded relation in terms of BMI: bike < walk < public transport < motorcycle or moped < e-bike < car. Self-reported physical activity from transport (walking, cycling, e-biking) was not found to be a mediator in the association between transport mode usage and BMI (Figure S2). A series of sensitivity analyses confirmed our results (Figure 1): differences between male and female were small, excluding participants older than 60 did not change our conclusions; and when only considering people with a healthy BMI (below $25 \mathrm{~kg} / \mathrm{m}^{2}$ ) the effects were smaller but largely in the same direction.

In frequent cyclists (defined as cycling for transport at least once per week) BMI was 0.375 $(95 \% \mathrm{Cl}-0.597$ to -0.153$)$ points lower compared to a non-cyclist; and being an occasional 
This is a post-peer-review, pre-copyedit version of an article published in Environment International. The final authenticated version is available online at: https://doi.org/10.1016/i.envint.2018.06.023

cyclist (defined as cycling for transport less than once per week) was not associated with BMI (Table 2, Figure 1).

\section{Longitudinal analysis}

No statistically significant associations between change in BMI and change in transport mode usage were found in the fully-adjusted models (Table 2). However, results from unadjusted, partly adjusted and fully adjusted models (models $0-2$ ) suggest that BMI decreases somewhat when cycling frequency increases $(-0.004,95 \% \mathrm{Cl}-0.011$ to 0.003$)$, and $\mathrm{BMI}$ increases when car usage increases $(0.005,95 \% \mathrm{Cl}-0.005$ to 0.015$)$. In addition the results suggest that public transport use decreases BMI $(-0.005,95 \% \mathrm{Cl}-0.012$ to 0.002$)$, which confirms previous work that showed public transport use is often combined with active mobility. Excluding participants with less than 1 year between $t_{0}$ and $t_{1}$ resulted in a slightly larger change in BMI (Figure 1). Due to the less frequent use of motorcycle and e-bike compared to other modes, confidence intervals were wider and mostly not statistically significant.

Statistically significant reductions in BMI were seen in the fully-adjusted model in both frequent cyclists who maintained cycling $(-0.181,95 \% \mathrm{Cl}-0.322$ to -0.040$)$ and occasional/noncyclists who increased cycling $(-0.303,95 \% \mathrm{Cl}-0.530$ to -0.077$)$ (Table 2$)$. A frequent cyclist who stopped cycling significantly increased their BMI $(0.417,95 \% \mathrm{Cl} 0.033$ to 0.802$)$ (Table S9, Figure S3). Taking up at least some cycling reduced BMI $(-0.414,95 \% \mathrm{Cl}-0.760$ to -0.068$)$ (Table S9, Figure S3). Findings were robust after performing several sensitivity analyses (Figure 1).

City was included as a random effect in all models: an analysis by city gave mainly nonsignificant results because of the smaller sample sizes and wider confidence intervals; a post hoc meta-analysis gave similar estimates as the original mixed models (Figure S4). 
This is a post-peer-review, pre-copyedit version of an article published in Environment International. The final authenticated version is available online at: https://doi.org/10.1016/i.envint.2018.06.023

\section{Table 2: Results from the linear mixed-effects models (cross-sectional and longitudinal analysis). Full models are presented in the supplemental material.}

Model 0: unadjusted

Model 1: partly adjusted ${ }^{+}$

Model 2: fully adjusted \# Coefficient $(95 \% \mathrm{Cl})$ p-value Coefficient $(95 \% \mathrm{Cl})$

\section{Cross-sectional analyses $(n=7380)$}

${ }^{\dagger}$ Model 1 adjusted for sex, age, education level, city as random effect

\#Model 2 adjusted for sex, age, education level, self-rated health, occupational physical activity, leisure-time physical activity, sedentary time, city as random effect

\begin{tabular}{|c|c|c|c|c|c|c|}
\hline \multicolumn{7}{|c|}{ (a) Association between BMI $\left(\mathrm{kg} / \mathrm{m}^{2}\right)$ and transport mode usage (difference in BMI per additional day per month) (Full model in Table S5) } \\
\hline Bike & $-0.020(-0.030$ to -0.010$)$ & $<0.0001$ & $-0.025(-0.035$ to -0.015$)$ & $<0.0001$ & $-0.010(-0.020$ to -0.0002$)$ & 0.046 \\
\hline Car & $0.041(0.029$ to 0.054$)$ & $<0.0001$ & 0.025 (0.012 to 0.038$)$ & $<0.0001$ & $0.027(0.015$ to 0.040$)$ & $<0.0001$ \\
\hline E-bike & 0.036 (0.010 to 0.062$)$ & 0.007 & $0.023(-0.002$ to 0.048$)$ & 0.072 & $0.021(-0.003$ to 0.045$)$ & 0.086 \\
\hline Motorcycle / moped & $-0.001(-0.020$ to 0.018$)$ & 0.914 & $0.013(-0.006$ to 0.033$)$ & 0.168 & $0.019(0.0001$ to 0.037$)$ & 0.049 \\
\hline Public transport & $-0.015(-0.026$ to -0.004$)$ & 0.008 & $0.009(-0.002$ to 0.020$)$ & 0.094 & $0.007(-0.003$ to 0.018$)$ & 0.173 \\
\hline Walk & $-0.003(-0.015$ to 0.008$)$ & 0.560 & $-0.008(-0.019$ to 0.004$)$ & 0.187 & $-0.004(-0.015$ to 0.007$)$ & 0.455 \\
\hline \multicolumn{7}{|c|}{ (b) Association between BMI (kg/m²) and cycling frequency (Full model in Table S6) } \\
\hline Non-cyclist & 0 & -- & 0 & -- & 0 & -- \\
\hline Occasional cyclist & $-0.156(-0.422$ to 0.109$)$ & 0.248 & $-0.164(-0.419$ to 0.092$)$ & 0.209 & $0.030(-0.216$ to 0.277$)$ & 0.811 \\
\hline Frequent cyclist & $-0.492(-0.715$ to -0.268$)$ & $<0.0001$ & $-0.779(-1.007$ to -0.552$)$ & $<0.0001$ & $-0.375(-0.597$ to -0.153$)$ & 0.0009 \\
\hline
\end{tabular}

Longitudinal analyses $(\mathbf{n}=\mathbf{2 3 1 6})$

${ }^{\dagger}$ Model 1 adjusted for sex, age at baseline, baseline education level, baseline BMI, city as random effect

\#Model 2 adjusted for sex, age at baseline, baseline education level, baseline BMI, change in self-rated health, change in lifestyle, change in occupational physical activity, change in leisure-time physical activity, change in sedentary time, time between $t_{0}$ and $t_{1}$, city as random effect

\begin{tabular}{|c|c|c|c|c|c|c|}
\hline \multicolumn{7}{|c|}{ (c) Association between change in BMI ( $\mathrm{kg} / \mathrm{m}^{2}$ ) and change in transport mode usage (change in BMI per additional day per month) (Full model in Table S7) } \\
\hline Bike & $-0.005(-0.012$ to 0.002$)$ & 0.203 & $-0.005(-0.012$ to 0.002$)$ & 0.162 & $-0.004(-0.011$ to 0.003$)$ & 0.300 \\
\hline Car & $0.009(-0.001$ to 0.019$)$ & 0.072 & $0.008(-0.002$ to 0.018$)$ & 0.123 & $0.005(-0.005$ to 0.015$)$ & 0.318 \\
\hline E-bike & $0.014(-0.001$ to 0.029$)$ & 0.075 & $0.014(-0.001$ to 0.028$)$ & 0.074 & $0.013(-0.001$ to 0.028$)$ & 0.077 \\
\hline Motorcycle / moped & $-0.003(-0.019$ to 0.013$)$ & 0.751 & $-0.001(-0.017$ to 0.015$)$ & 0.928 & $-0.001(-0.017$ to 0.015$)$ & 0.911 \\
\hline Public transport & $-0.005(-0.012$ to 0.003$)$ & 0.243 & $-0.003(-0.011$ to 0.004$)$ & 0.388 & $-0.005(-0.012$ to 0.002$)$ & 0.191 \\
\hline Walk & $-0.003(-0.009$ to 0.003$)$ & 0.294 & $-0.002(-0.008$ to 0.004$)$ & 0.465 & $-0.001(-0.007$ to 0.005$)$ & 0.776 \\
\hline \multicolumn{7}{|c|}{ (d) Association between change in $\mathrm{BMI}\left(\mathrm{kg} / \mathrm{m}^{2}\right)$ and change in cycling frequency (Full model in Table S8) } \\
\hline Stable: Never & 0 & -- & 0 & -- & 0 & -- \\
\hline Less cycling & $0.043(-0.131$ to 0.218$)$ & 0.627 & $0.034(-0.138$ to 0.206$)$ & 0.698 & $0.010(-0.160$ to 0.180$)$ & 0.906 \\
\hline More cycling & $-0.247(-0.478$ to -0.017$)$ & 0.035 & $-0.279(-0.507$ to -0.051$)$ & 0.016 & $-0.303(-0.530$ to -0.077$)$ & 0.009 \\
\hline Stable: Frequent & $-0.136(-0.277$ to 0.006$)$ & 0.060 & $-0.161(-0.303$ to -0.019$)$ & 0.026 & $-0.181(-0.322$ to -0.040$)$ & 0.012 \\
\hline Stable: Occasional & $-0.116(-0.307$ to 0.076$)$ & 0.236 & $-0.099(-0.288$ to 0.089$)$ & 0.302 & $-0.085(-0.272$ to 0.101$)$ & 0.371 \\
\hline
\end{tabular}



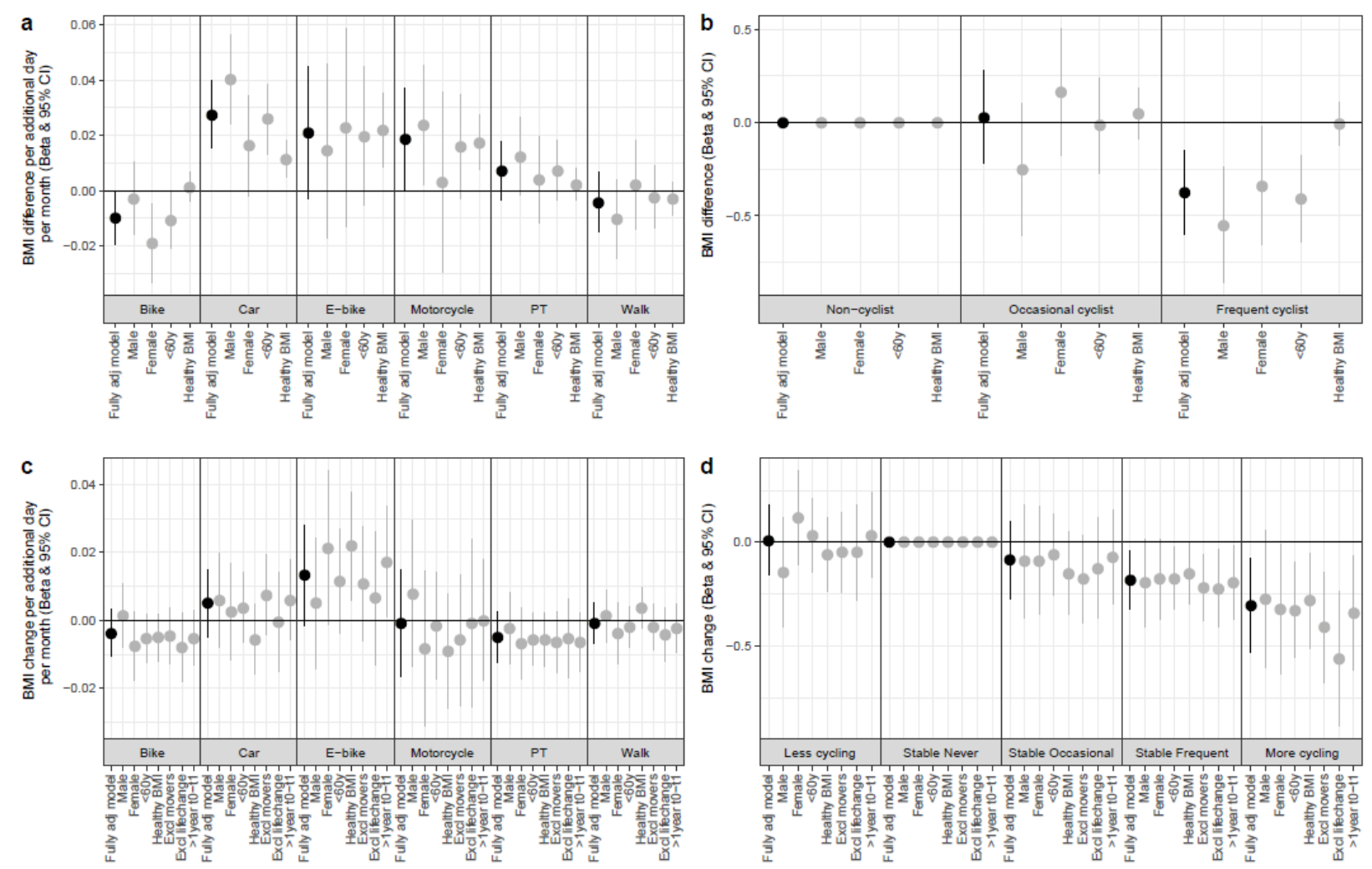

Figure 1: Effect sizes from the fully adjusted cross-sectional $(a, b)$ and longitudinal (c, d) models and sensitivity analyses. Panels a and $c$ use transport mode usage as exposure variable; in panels $b$ and $d$ cycling frequency is used as exposure variable. The dots indicate differences $(a, b)$ or changes $(c, d)$ in BMI and the error bars indicate $95 \% \mathrm{Cls}$. 
This is a post-peer-review, pre-copyedit version of an article published in Environment International. The final authenticated version is available online at: https://doi.org/10.1016/j.envint.2018.06.023

\section{Discussion}

In this large multicentre study, we found associations between transport mode choice and BMI. We showed that cycling is associated with lower BMI, and car use with higher BMI. When participants stopped or reduced frequency of cycling, their BMI increased, and when they increased/took up cycling, it decreased. Our analyses further suggested a graded relationship with the lowest BMI in cyclists, followed by walking, public transport, motorcycle or moped, ebike, and the highest BMI for car users. In both the cross-sectional (comparison between modes) and the longitudinal (change over time within an individual) analysis we found these associations. However, the effect sizes were smaller in the longitudinal analysis hinting at the presence of reverse causality, or hampered by the limited time between baseline and final assessment. A number of sensitivity analyses confirmed our main results.

The cross-sectional analysis showed that a person cycling daily has a BMI of $1.11 \mathrm{~kg} / \mathrm{m}^{2}$ lower than someone who drove a car daily. According to Joshi et al. (2017) this difference in BMI would correspond to a lower life expectancy for car drivers of almost 8 months. For an average individual in our sample a difference in BMI of $1.11 \mathrm{~kg} / \mathrm{m}^{2}$ accounted to a weight difference of $3.5 \mathrm{~kg}$ for men and $3.1 \mathrm{~kg}$ for women (Figure S5). In a cross-sectional study by Flint and Cummins (Flint and Cummins 2016) in older adults this was 5 and $4.4 \mathrm{~kg}$ respectively. In an Australian study, older men and women who consistently walked or cycled for 6 years continuously had a lower BMI (range: -2.15 up to $-3.20 \mathrm{~kg} / \mathrm{m}^{2}$ ) compared to users of private motor vehicles (Turrell and others 2017). Our longitudinal analysis showed smaller, but still mostly statistically significant effects: men weighed about $0.75 \mathrm{~kg}$ less after the follow-up period compared to the start of the study period when switching from car driving on 30 days per month to cycling on $\mathbf{3 0}$ days per month; for women this was less. A comparable result was found in a longitudinal study in the UK where a weight loss of $1 \mathrm{~kg}$ was observed for men switching from car to active or public modes, for women this was $0.8 \mathrm{~kg}$ (Flint and others 2016); another UK study found for the same switch a decrease in BMI of $0.32 \mathrm{~kg} / \mathrm{m}^{2}$ which was similar to our study (Martin and others 2015). In a longitudinal study over 8 years in China, men gained $1.8 \mathrm{~kg}$ when acquiring a car (Bell and others 2002). Likewise, giving up one's car lead to a $3 \mathrm{~kg}$ reduction in body weight after 6 years in US adults (Smart 2018). The mediation analysis in the cross-sectional models indicated that lower BMI in cyclists was unlikely to be entirely caused by increased transport-related physical activity. Self-selection or lifestyle, or other residual confounding from dietary energy intake might explain the remaining difference. Individuals that dropped out of the study were not systematically different in the outcome 
This is a post-peer-review, pre-copyedit version of an article published in Environment International. The final authenticated version is available online at: https://doi.org/10.1016/j.envint.2018.06.023

variable (BMI) from participants in both waves of the survey and therefore could not explain the difference in results.

$\mathrm{BMI}$ increases with age, at rates of approximately 0.06 to $0.20 \mathrm{~kg} / \mathrm{m}^{2}$ per year (Kim and others 2017). In our study, the average follow-up period lasted for 492 days, resulting in a BMI increase of $0.109 \mathrm{~kg} / \mathrm{m}^{2}$ (transport mode usage model) or $0.139 \mathrm{~kg} / \mathrm{m}^{3}$ (cycling frequency model). This was in the same order of magnitude as someone who continued to cycle occasionally $\left(-0.085 \mathrm{~kg} / \mathrm{m}^{2}\right)$ meaning that these individuals did not lower BMI, but they kept their BMI stable, contrary to the general population that increased BMI over the follow-up period. Taking up cycling thus prevents it getting worse in those that are already overweight or obese, and it prevents those who are normal weight from becoming overweight or obese. This leads to lower risks for a number of chronic diseases, including diabetes, cardiovascular diseases and cancer. The rise in the use of active transport modes may therefore counteract the increasing prevalence of overweight and obesity and the related health impact in cities in both high- and low-income countries.

We mainly focussed on the extreme mode switch from car to bike, but also for some other modes near-significant effects were found. Although the sample of e-bikers was small, riding an e-bike was associated with higher BMI. This finding could complement a previous study that found that older adults with a higher BMI were more likely to be an e-bike-user (Van Cauwenberg and others in press). This would indicate the presence of self-selection. In the longitudinal analysis, we hypothesize that more frequent use of an e-bike leads to a higher BMI through less regular biking. However, it is unlikely that all of the weight gain was the result of reduced physical activity, as e-biking still requires moderate to vigorous levels of physical activity (Berntsen and others 2017; Langford and others 2017). Using public transport resulted in a lower BMI than private motorized transport; this confirmed most previous studies who found lower risks of being overweight in public transport users (Liao and others 2016; MacDonald and others 2010; Smart 2018). Pedestrians and cyclists were split in our analyses in contrast to some previous studies (Flint and others 2014; Liao and others 2016; Martin and others 2015). Cycling requires more energy per minute than walking and it was previously found that cycling commuters were overall more physically active compared to pedestrians (Celis-Morales and others 2017b; Turrell and others 2017). This was reflected in our findings when considering BMI: pedestrians had a higher BMI compared to cyclists, but a lower BMI compared to car drivers, consistent with the literature (Flint and Cummins 2016; Mytton and others 2016). We included all walking trips, and not just walking as the main mode of transport or as the main commute mode; because walking trips were often short in length, this may 
This is a post-peer-review, pre-copyedit version of an article published in Environment International. The final authenticated version is available online at: https://doi.org/10.1016/j.envint.2018.06.023

have pushed our estimates to the null. For instance, Frank and colleagues (Frank and others 2004) found that each additional kilometre walked per day was associated with a $4.8 \%$ reduction in the risk of obesity. The overall reduction in active mobility at $t_{1}$ compared to $t_{0}$ might be caused by the timing of the final questionnaire, which was administered during the European wintertime, or by other secular factors like changes in the built environment or local transport policies (Goodman and others 2014; Panter and others 2016).

A limitation of our study was the self-reported height and weight: Height usually gets overestimated while weight gets underestimated; as a result, BMI gets underestimated by around 0 to 1 points (Gorber and others 2007). Heavier people tend to underestimate more (Gorber and others 2007). The difference between true BMI and reported BMI increases at older ages (Kuczmarski and others 2001). In our study, car drivers were heavier, and as heavier people tend to underestimate their weight, a possible bias would have underestimated the effect. Moreover, a validation sub-study found that self-reported weights were well correlated to directly measured weights, and that the difference between both was non-differential between transport modes. Recall bias might also have affected the transport mode usage and physical activity reporting. We had no information on dietary energy intake, which could lead to residual confounding; however in a previous study from Flint and Cummins (2016), diet did not impact the BMI to active mobility relationship. Other studies also found that extra physical activity was not compensated for by additional food intake (Donnelly and others 2014; Schubert and others 2013). Therefore, we hypothesized that diet was not associated to the exposure and was not an effect of the exposure, leading to no or only limited residual confounding in our study.

The sample is representative of the general population for sex, but is not representative in for instance education, ethnicity, or BMI, which may indicate healthy volunteer selection bias (Table S1). Only in Oerebro an effort was made for random sampling, whereas in other cities an opportunistic recruitment strategy was followed (Dons and others 2015). Since cyclists were oversampled on purpose, the prevalence of cycling is not representative for the general population; nevertheless, our estimates should be generally valid.

Outcome and exposure variables were reported at two time points - because of this design we could not differentiate between shorter-term effects and effects that are more persistent. Periodic effects could not be excluded, for which we tried to address by including relevant time-varying covariates like physical activity level and self-rated health. Unfortunately in our observational study the change in transport mode usage was not exogenous because people self-selected themselves to change their transport mode (van de Coevering and others 2015). 
The multicentre approach in different countries with different obesity prevalence, physical activity levels, and active mobility use, added value to the analysis. A longitudinal and multicentre study design is generally considered more complex, expensive, and time consuming, but our analysis clearly provided additional insights also on causal inferences compared to the cross-sectional analysis only (van de Coevering and others 2015). We accounted for a number of influencing factors that were often not available in previous studies, like leisure-time and occupational physical activity, or health status.

In conclusion, we found statistically significant associations between transport mode choice and BMI. Cyclists weighed less than their non-active peers; and people that start or increase cycling will most likely lose weight and vice versa. Promoting active mobility may therefore provide an opportunity to fight the overweight and obesity epidemic, contributing in turn to reduce the very high burden of non-communicable diseases. 
This is a post-peer-review, pre-copyedit version of an article published in Environment International. The final authenticated version is available online at: https://doi.org/10.1016/i.envint.2018.06.023

\section{Acknowledgements}

This work was supported by the European project Physical Activity through Sustainable Transportation Approaches (PASTA). PASTA (http://www.pastaproject.eu/) was a four-year project funded by the European Union's Seventh Framework Program (EU FP7) under European Commission - Grant Agreement No. 602624. Evi Dons is supported by a postdoctoral scholarship from FWO - Research Foundation Flanders. Michelle Laeremans holds a joint PASTA/VITO PhD scholarship.

\section{Declaration of interests}

The authors declare no competing interests.

\section{Role of funding source}

The funders of the study had no role in study design, data collection, data analysis, data interpretation, or writing of the publication. The corresponding author had full access to all the data in the study and had final responsibility for the decision to submit for publication.

\section{Ethics committee approval}

Ethics approval was obtained for all aspects of the study by the local ethics committees in the countries where the work was conducted, and sent to the European Commission before the start of the survey/study. The following committees approved the study:

- $\quad$ Ethics board of the University Hospital of Antwerp (Belgium) on October 20, 2014

- $\quad$ Clinical Research Ethics Committee of the Municipal Health Care (Barcelona - Spain) on October 1, 2014

- $\quad$ Imperial College Research Ethics Committee (London - UK) on November 20, 2014

- $\quad$ Regional ethical board, situated at the University of Lund (Oerebro - Sweden) on April 9, 2015

- $\quad$ RSM - Roma Servizi per la Mobilità and the Air quality Commission of Roma Capitale Administration (Rome - Italy) on November 24, 2014

- $\quad$ The Austrian Data Processing Register (Vienna - Austria) on September 26, 2014

- $\quad$ Kantonale Ethikkommission Zürich (Switzerland) on October 28, 2014 
This is a post-peer-review, pre-copyedit version of an article published in Environment International. The final authenticated version is available online at: https://doi.org/10.1016/i.envint.2018.06.023

\section{References}

Aadahl, M.; Kjaer, M.; Jorgensen, T. Associations between overall physical activity level and cardiovascular risk factors in an adult population. Eur J Epidemiol. 22:369-378; 2007

Aires, N.; Selmer, R.; Thelle, D. The validity of self-reported leisure time physical activity, and its relationship to serum cholesterol, blood pressure and body mass index. A population based study of 332,182 men and women aged 40-42 years. Eur J Epidemiol. 18:479-485; 2003

Allender, S.; Hutchinson, L.; Foster, C. Life-change events and participation in physical activity: a systematic review. Health Promot Int. 23:160-172; 2008

Bassett, D.R.; Jr., J.P.; Buehler, R.; Thompson, D.L.; Crouter, S.E. Walking, Cycling, and Obesity Rates in Europe, North America, and Australia. J Phys Act Health. 5:795-814; 2008

Bell, A.C.; Ge, K.; Popkin, B.M. The road to obesity or the path to prevention: Motorized transportation and obesity in China. Obes Res. 10:277-283; 2002

Berghöfer, A.; Pischon, T.; Reinhold, T.; Apovian, C.M.; Sharma, A.M.; Willich, S.N. Obesity prevalence from a European perspective: a systematic review. BMC Public Health. 8:200; 2008

Berntsen, S.; Malnes, L.; Langaker, A.; Bere, E. Physical activity when riding an electric assisted bicycle. International Journal of Behavioral Nutrition and Physical Activity. 14; 2017

Braun, L.M.; Rodriguez, D.A.; Song, Y.; Meyer, K.A.; Lewis, C.E.; Reis, J.P.; Gordon-Larsen, P. Changes in walking, body mass index, and cardiometabolic risk factors following residential relocation: Longitudinal results from the CARDIA study. J Transp Health. 3:426-439; 2016

Bull, F.C.; Maslin, T.S.; Armstrong, T. Global Physical Activity Questionnaire (GPAQ): Nine country reliability and validity study. J Phys Act Health. 6:790-804; 2009

Celis-Morales, C.; Livingstone, K.M.; Affleck, A.; Navas-Carretero, S.; San-Cristobal, R.; Martinez, J.A.; Marsaux, C.F.M.; Saris, W.H.M.; O’Donovan, C.B.; Forster, H.; Woolhead, C.; Gibney, E.R.; Walsh, M.C.; Brennan, L.; Gibney, M.; Moschonis, G.; Lambrinou, C.-P.; Mavrogianni, C.; Manios, Y.; Macready, A.L.; Fallaize, R.; Lovegrove, J.A.; Kolossa, S.; Daniel, H.; Traczyk, I.; Drevon, C.A.; Mathers, J.C. Correlates of overall and central obesity in adults from seven European countries: findings from the Food4Me Study. Eur J Clin Nutr. 72:207-219; 2017a

Celis-Morales, C.; Lyall, D.M.; Welsh, P.; Anderson, J.; Steell, L.; Guo, Y.B.; Maldonado, R.; Mackay, D.F.; Pell, J.P.; Sattar, N.; Gill, J.M.R. Association between active commuting and incident cardiovascular disease, cancer, and mortality: prospective cohort study. BMJ. 357; 2017b

Donnelly, J.E.; Herrmann, S.D.; Lambourne, K.; Szabo, A.N.; Honas, J.J.; Washburn, R.A. Does increased exercise or physical activity alter ad-libitum daily energy intake or macronutrient composition in healthy adults? A systematic review. PLoS One. 9:e83498; 2014

Dons, E.; Gotschi, T.; Nieuwenhuijsen, M.; de Nazelle, A.; Anaya, E.; Avila-Palencia, I.; Brand, C.; ColeHunter, T.; Gaupp-Berghausen, M.; Kahlmeier, S.; Laeremans, M.; Mueller, N.; Orjuela, J.P.; Raser, E.; Rojas-Rueda, D.; Standaert, A.; Stigell, E.; Uhlmann, T.; Gerike, R.; Int Panis, L. Physical Activity through Sustainable Transport Approaches (PASTA): protocol for a multi-centre, longitudinal study. BMC Public Health. 15:1126; 2015

Ekelund, U.; Brage, S.; Besson, H.; Sharp, S.; Wareham, N.J. Time spent being sedentary and weight gain in healthy adults: reverse or bidirectional causality? Am J Clin Nutr. 88:612-617; 2008

Ekelund, U.; Kolle, E.; Steene-Johannessen, J.; Dalene, K.E.; Nilsen, A.K.O.; Anderssen, S.A.; Hansen, B.H. Objectively measured sedentary time and physical activity and associations with body weight gain: does body weight determine a decline in moderate and vigorous intensity physical activity? Int J Obes. 41:1769-1774; 2017

Faulkner, G.E.J.; Buliung, R.N.; Flora, P.K.; Fusco, C. Active school transport, physical activity levels and body weight of children and youth: A systematic review. Prev Med. 48:3-8; 2009

Flint, E.; Cummins, S. Active commuting and obesity in mid-life: cross-sectional, observational evidence from UK Biobank. Lancet Diabetes Endocrinol. 4:420-435; 2016

Flint, E.; Cummins, S.; Sacker, A. Associations between active commuting, body fat, and body mass index: population based, cross sectional study in the United Kingdom. BMJ. 349; 2014

Flint, E.; Webb, E.; Cummins, S. Change in commute mode and body-mass index: prospective, longitudinal evidence from UK Biobank. Lancet Public Health. 1:e46-e55; 2016

Frank, L.D.; Andresen, M.A.; Schmid, T.L. Obesity relationships with community design, physical activity, and time spent in cars. Am J Prev Med. 27:87-96; 2004

Goodman, A.; Sahlqvist, S.; Ogilvie, D. New walking and cycling routes and increased physical activity: one- and 2-year findings from the UK iConnect Study. Am J Public Health. 104:e38-46; 2014 
This is a post-peer-review, pre-copyedit version of an article published in Environment International. The final authenticated version is available online at: https://doi.org/10.1016/j.envint.2018.06.023

Gorber, S.C.; Tremblay, M.; Moher, D.; Gorber, B. Diagnostic in obesity comorbidities - A comparison of direct vs. self-report measures for assessing height, weight and body mass index: a systematic review. Obes Rev. 8:307-326; 2007

Joshi, P.K.; Pirastu, N.; Kentistou, K.A.; Fischer, K.; Hofer, E.; Schraut, K.E.; Clark, D.W.; Nutile, T.; Barnes, C.L.K.; Timmers, P.R.H.J.; Shen, X.; Gandin, I.; McDaid, A.F.; Hansen, T.F.; Gordon, S.D.; Giulianini, F.; Boutin, T.S.; Abdellaoui, A.; Zhao, W.; Medina-Gomez, C.; Bartz, T.M.; Trompet, S.; Lange, L.A.; Raffield, L.; van der Spek, A.; Galesloot, T.E.; Proitsi, P.; Yanek, L.R.; Bielak, L.F.; Payton, A.; Murgia, F.; Concas, M.P.; Biino, G.; Tajuddin, S.M.; Seppälä, I.; Amin, N.; Boerwinkle, E.; Børglum, A.D.; Campbell, A.; Demerath, E.W.; Demuth, I.; Faul, J.D.; Ford, I.; Gialluisi, A.; Gögele, M.; Graff, M.; Hingorani, A.; Hottenga, J.-J.; Hougaard, D.M.; Hurme, M.A.; Ikram, M.A.; Jylhä, M.; Kuh, D.; Ligthart, L.; Lill, C.M.; Lindenberger, U.; Lumley, T.; Mägi, R.; Marques-Vidal, P.; Medland, S.E.; Milani, L.; Nagy, R.; Ollier, W.E.R.; Peyser, P.A.; Pramstaller, P.P.; Ridker, P.M.; Rivadeneira, F.; Ruggiero, D.; Saba, Y.; Schmidt, R.; Schmidt, H.; Slagboom, P.E.; Smith, B.H.; Smith, J.A.; Sotoodehnia, N.; Steinhagen-Thiessen, E.; van Rooij, F.J.A.; Verbeek, A.L.; Vermeulen, S.H.; Vollenweider, P.; Wang, Y.; Werge, T.; Whitfield, J.B.; Zonderman, A.B.; Lehtimäki, T.; Evans, M.K.; Pirastu, M.; Fuchsberger, C.; Bertram, L.; Pendleton, N.; Kardia, S.L.R.; Ciullo, M.; Becker, D.M.; Wong, A.; Psaty, B.M.; van Duijn, C.M.; Wilson, J.G.; Jukema, J.W.; Kiemeney, L.; Uitterlinden, A.G.; Franceschini, N.; North, K.E.; Weir, D.R.; Metspalu, A.; Boomsma, D.I.; Hayward, C.; Chasman, D.; Martin, N.G.; Sattar, N.; Campbell, H.; Esko, T.; Kutalik, Z.; Wilson, J.F. Genome-wide meta-analysis associates HLA-DQA1/DRB1 and LPA and lifestyle factors with human longevity. Nature Communications. 8:910; 2017

Kim, Y.; Lee, J.-M.; Kim, J.; Dhurandhar, E.; Soliman, G.; Wehbi, N.K.; Canedy, J. Longitudinal associations between body mass index, physical activity, and healthy dietary behaviors in adults: A parallel latent growth curve modeling approach. PLoS One. 12:e0173986; 2017

Kuczmarski, M.F.; Kuczmarski, R.J.; Najjar, M. Effects of age on validity of self-reported height, weight, and body mass index. J Am Diet Assoc. 101:28-34; 2001

Langford, B.C.; Cherry, C.R.; Bassett, D.R.; Fitzhugh, E.C.; Dhakal, N. Comparing physical activity of pedalassist electric bikes with walking and conventional bicycles. J Transp Health. 6:463-473; 2017

Liao, Y.; Tsai, H.-H.; Wang, H.-S.; Lin, C.-P.; Wu, M.-C.; Chen, J.-F. Travel mode, transportation-related physical activity, and risk of overweight in Taiwanese adults. J Transp Health. 3:220-225; 2016

MacDonald, J.M.; Stokes, R.J.; Cohen, D.A.; Kofner, A.; Ridgeway, G.K. The effect of light rail transit on body mass index and physical activity. Am J Prev Med. 39:105-112; 2010

Martin, A.; Panter, J.; Suhrcke, M.; Ogilvie, D. Impact of changes in mode of travel to work on changes in body mass index: evidence from the British Household Panel Survey. J Epidemiol Community Health. 69:753; 2015

Mytton, O.T.; Panter, J.; Ogilvie, D. Longitudinal associations of active commuting with body mass index. Prev Med. 90:1-7; 2016

Panter, J.; Heinen, E.; Mackett, R.; Ogilvie, D. Impact of new transport infrastructure on walking, cycling, and physical activity. Am J Prev Med. 50:E45-E53; 2016

Physical Activity Guidelines Advisory Committee. Physical Activity Guidelines Advisory Committee Report, 2008. Washington DC: U.S. Department of Health and Human Services; 2008

Prentice, A.M.; Jebb, S.A. Obesity in Britain - Gluttony or sloth. Br Med J. 311:437-439; 1995

Pucher, J.; Buehler, R.; Bassett, D.R.; Dannenberg, A.L. Walking and cycling to health: A comparative analysis of city, state, and international data. Am J Public Health. 100:1986-1992; 2010

Schubert, M.M.; Desbrow, B.; Sabapathy, S.; Leveritt, M. Acute exercise and subsequent energy intake. A meta-analysis. Appetite. 63:92-104; 2013

Smart, M.J. Walkability, transit, and body mass index: A panel approach. J Transp Health. (in press); 2018

Turrell, G.; Hewitt, B.A.; Rachele, J.N.; Giles-Corti, B.; Brown, W.J. Prospective trends in body mass index by main transport mode, 2007-2013. J Transp Health. (in press); 2017

Van Cauwenberg, J.; De Bourdeaudhuij, I.; Clarys, P.; de Geus, B.; Deforche, B. Older e-bike users: demographic, health, mobility characteristics, and cycling levels. Med Sci Sports Exerc. Publish Ahead of Print; in press

van de Coevering, P.; Maat, K.; van Wee, B. Multi-period research designs for identifying causal effects of built environment characteristics on travel behaviour. Transp Rev. 35:512-532; 2015

VanderWeele, T.J. Mediation Analysis: A Practitioner's Guide. in: Fielding J.E., ed. Annual Review of Public Health, Vol 37; 2016 
This is a post-peer-review, pre-copyedit version of an article published in Environment International. The final authenticated version is available online at: https://doi.org/10.1016/i.envint.2018.06.023

Wanner, M.; Götschi, T.; Martin-Diener, E.; Kahlmeier, S.; Martin, B.W. Active transport, physical activity, and body weight in adults. Am J Prev Med. 42:493-502; 2012

$\mathrm{Xu}, \mathrm{H} . ;$ Wen, L.M.; Rissel, C. The relationships between active transport to work or school and cardiovascular health or body weight. Asia Pac J Public Health. 25:298-315; 2013 